\title{
Fortalecimiento del rol de la CIDH en el proceso de supervisión de cumplimiento de sentencias y planteamiento de reparaciones ante la Corte IDH
}

\section{Strengthening the supervisory role of the Inter American Commission of Human Rights in the enforcement of decisions and reparation claims before the Inter American Court of Human Rights}

\author{
Jorge Calderón Gamboa \\ Corte Interamericana de Derechos Humanos, Costa Rica
}

\begin{abstract}
Abogado coordinador senior de la Corte Interamericana de Derechos Humanos y profesor de Derechos Humanos de la Universidad de Costa Rica (UCR). Obtuvo su Licenciatura en Derecho por la Universidad Iberoamericana (UIA) de México D.F y es LL.M. en Derecho Internacional por el Washington College of Law de la American University (AUWCL). Ha realizado cursos especializados en Derecho Penal Internacional en la Universidad de Leiden, La Haya y colaborado a nivel internacional con diversas organizaciones de la sociedad civil, con pueblos indígenas y campesinos. Asimismo, trabajó como visitador adjunto en la Comisión de Derechos Humanos del D.F (CDHDF). También fue abogado investigador de la Academia de Derechos Humanos y Derecho Internacional Humanitario del AU-WCL. Es autor de diversas publicaciones sobre derechos humanos, así como ha participado en diversos países en seminarios y cursos especializados en diversos temas de derechos humanos.
\end{abstract}

jorgecalderon@corteidh.or.cr

\section{RESUMEN}

La ejecución de las sentencias de la Corte Interamericana de Derechos Humanos a través de la implementación de las medidas de reparación integral dispuestas por la misma, representa la cristalización y efectividad del sistema interamericano de protección de los derechos humanos en su conjunto, es por ello que el autor plantea que la reformulación estratégica de la labor de la Comisión Interamericana de Derechos Humanos en estos procedimientos merece una reflexión. Este artículo analiza el rol de la Comisión Interamericana de Derechos Humanos en el procedimiento de supervisión de sentencias ante la Corte IDH, proponiendo una reformulación de su labor con base a su función como garante del orden público interamericano. Asimismo, propone el fortalecimiento de su rol en el planteamiento de reparaciones ante la Corte IDH.

Palabras clave: Corte Interamericana de Derechos Humanos - Comisión Interamericana de Derechos Humanos - reparaciones- supervisión de cumplimiento - orden público interamericano.

\begin{abstract}
The use of integral reparation measures within the enforcement of the Inter American Court of Human Rights decisions embodies the effectiveness of the Inter American system of human rights. Therefore the author suggests that a strategic reform of such measures in the Inter American Commission on Human Rights deserves reflection. The article analyses the Inter American Commission on Human Rights' supervision role of the Court's decisions in order to propose a reform based on its function as guarantor of the public order within the inter-American system. Moreover, it proposes the strengthening of such role in reparation claims before the Court.
\end{abstract}

Key words: Inter American Court of Human Rights - Inter American Commission on Human Rights reparations - enforcement supervision - inter American public order. 


\section{Introducción}

En el año 2009, la Comisión Interamericana de Derechos Humanos $(\mathrm{CIDH})^{1}$ y la Corte Interamericana de Derechos Humanos (Corte IDH) ${ }^{2}$ reformaron su reglamento, dando un nuevo rol a los peticionarios de los casos en el litigio ante la Corte IDH y posicionando a la CIDH como el "órgano del sistema interamericano", afianzando así, el equilibrio procesal entre las partes ${ }^{3}$. El nuevo rol de la CIDH también se materializa en el nuevo procedimiento ante la Corte IDH, donde la CIDH es garante del "orden público interamericano", especialmente frente al sometimiento del caso a la Corte IDH ${ }^{4}$ y el ofrecimiento de peritajes y preguntas en los debates ${ }^{5}$. Desde dicha reforma, la práctica reciente de la $\mathrm{CIDH}$ en los casos contenciosos ha consistido en exponer brevemente los hechos del caso y violaciones encontradas en su informe de fondo, así como plantear las razones por las cuales el caso representa cuestiones que conciernen al orden público interamericano ${ }^{6}$, lo que también ha sido retomado en las audiencias públicas ante el Tribunal. Así, mediante las resoluciones de convocatoria a audiencia, emitidas por el Presidente del Tribunal, se ha desarrollado este concepto. Si bien no existe una definición concreta del mismo, la Corte IDH ha señalado que para acreditar la existencia de un asunto que sea de interés del orden público interamericano, el objeto del peritaje propuesto por la CIDH no debe estar circunscrito a la situación u ordenamiento jurídico del país en cuestión y debe trascender los hechos específicos del caso en conocimiento de la Corte IDH, así como el interés concreto de las partes en litigio ${ }^{7}$. Asimismo, el artículo 45 del reglamento de la $\mathrm{CIDH}$, establece que en el

Reglamento aprobado por la CIDH en su $137^{\circ}$ período ordinario de sesiones, celebrado del 28 de octubre al 13 de noviembre de 2009; y modificado el 2 de septiembre de 2011 y en su $147^{\circ}$ período ordinario de sesiones, celebrado del 8 al 22 de marzo de 2013, para su entrada en vigor el 1 de agosto de 2013. Disponible [en línea] <http:// www.oas.org/es/cidh/mandato/Basicos/reglamentoCIDH.asp> [consulta: 4 de abril de 2014]. Ver artículo 45.2 del reglamento.

Aprobado por la Corte en su $85^{\circ}$ período ordinario de sesiones celebrado del 16 al 28 de noviembre del 2009. "Este nuevo Reglamento se enmarca en la segunda fase del diálogo y reflexión que emprendió la Corte Interamericana desde hace un tiempo con los diferentes actores y usuarios del sistema interamericano, la cual se ha reflejado en un proceso de consulta que se ha llevado a cabo mediante la convocatoria a todas las personas e instituciones que desearan participar, valiéndose para ello de distintos medios de información y mecanismos al alcance de todos. Tiene particular relevancia en esta etapa el diálogo y coordinación que se ha llevado a cabo con la Comisión Interamericana de Derechos Humanos". Disponible [en línea] <http://corteidh.or.cr/index.php/es/acerca-de/reglamento/reglamento-vigente> [consulta: 4 de abril de 2014].

3 En este sentido, "la principal reforma que el nuevo Reglamento introduce es el papel de la Comisión en el procedimiento ante la Corte. Respecto a este tema los diferentes actores del sistema que participaron en esta consulta se refirieron a la conveniencia de modificar algunos aspectos de la participación de la Comisión en el procedimiento ante la Corte, otorgando más protagonismo al litigio entre los representantes de las víctimas o presuntas víctimas y el Estado demandado, permitiendo así que la Comisión juegue más un papel de 'órgano del sistema interamericano' afianzando así, el equilibrio procesal entre las partes". Exposición de motivos, reglamento de la Corte IDH 2009. Disponible [en línea] <http://corteidh.or.cr/sitios/reglamento/nov_2009_motivos_esp.pdf> [consulta: 4 de abril de 2014].

$4 \quad$ El artículo 35.1.f del reglamento de la Corte IDH, señala que la CIDH deberá remitir "cuando se afecte de manera relevante el orden público interamericano de los derechos humanos, la eventual designación de peritos, indicando el objeto de sus declaraciones y acompañando su hoja de vida".

El artículo 52.3 del reglamento de la Corte IDH, establece que: "la Comisión podrá interrogar a los peritos que propuso conforme al artículo 35.1.f del presente Reglamento, y a los de las presuntas víctimas, del Estado demandado y, en su caso, del Estado demandante, si la Corte lo autoriza a solicitud fundada de la Comisión, cuando se afecte de manera relevante el orden público interamericano de los derechos humanos y su declaración verse sobre alguna materia contenida en un peritaje ofrecido por la Comisión".

6 Véase "sometimientos de casos". Disponible [en línea] <http://www.oas.org/es/cidh/decisiones/demandas.asp> [consulta: 4 de abril de 2014].

Corte IDH. Caso Brewer Carías Vs. Venezuela. Resolución del Presidente de la Corte Interamericana de Derechos humanos de 31 de julio de 2011, párr. 84; caso Atala Riffo e hijas Vs. Chile. Resolución del Presidente de la Corte Interamericana de Derechos humanos de 7 de julio de 2011, párr. 13 y; caso Rodríguez Vera y otros Vs. Colombia. 
sometimiento del caso, la CIDH considerará los siguientes elementos, inter alia: "c. la necesidad de desarrollar o aclarar la jurisprudencia del sistema; y d. el eventual efecto de la decisión en los ordenamientos jurídicos de los Estados miembros".

De ello se desprende que el rol a cargo de la CIDH frente a la Corte IDH dispone la presentación de problemáticas que puedan -además de resolver el caso en cuestión- trascender situaciones generales o estructurales para los países de la región.

Por otra parte, en años recientes, los Estados de las Américas, las organizaciones civiles, acadé$\operatorname{micos}^{8}$, y órganos de la Organización de Estados Americanos (OEA), incluyendo la creación de un Grupo de Trabajo Especial de Reflexión, realizaron un arduo proceso de discusión sobre la necesidad de fortalecer el Sistema Interamericano de Derechos Humanos (SIDH) ${ }^{9}$. Los puntos en debate se relacionaban con la designación del Secretario Ejecutivo de la CIDH, las medidas cautelares, el procedimiento en la tramitación de peticiones individuales y soluciones amistosas, los criterios para la construcción del capítulo IV del informe anual de la CIDH, el fortalecimiento en las tareas de promoción de los derechos humanos, y el fortalecimiento financiero del sistema ${ }^{10}$. En especial, con motivo de estas reflexiones, en el año 2013, la CIDH reformó su reglamento atendiendo algunas de las cuestiones planteadas ${ }^{11}$, particularmente, respecto de las medidas cautelares y el procedimiento de peticiones ante la $\mathrm{CIDH}$. El único aspecto relacionado con el trámite ante la Corte IDH que se modificó, se relaciona con la solicitud de medidas provisionales y la disposición de prórrogas a los Estados para el sometimiento de casos ante el tribunal ${ }^{12}$. Asimismo, la OEA incrementó módicamente el presupuesto destinado a la labor de los principales órganos en la materia ${ }^{13}$. En dicho proceso no se abordaron como temáticas principales el procedimiento de casos ante la Corte IDH ni las facultades de la CIDH al respecto. No obstante, frente al gran desafío que tiene la $\mathrm{CIDH}$ con el aumento de peticiones y la atención de las diversas problemáticas en materia de derechos humanos en la región, se hace necesario que la $\mathrm{CIDH}$-como órgano garante del orden público interamericano- pueda reformular algu-

Resolución del Presidente de la Corte Interamericana de Derechos Humanos de 16 de octubre de 2013, párrs. 60 y 64 .

8 Veáse, por ejemplo: HUMAN RIGHTS BRIEF. "The Future of the Inter-American System of Human Rights". Vol. 20, 2013; CEJIL. "Aportes para la Reflexión sobre posibles reformas al funcionamiento de la CIDH y la Corte IDH", octubre 2008; DULITZKY, Ariel. "La OEA y los derechos humanos, nuevos perfiles para el SIDH". Diálogo Político, Vol. 25, No.4, 2008, pp.69-108 y; HUMAN RIGHTS CLINIC. Maximizando la Justicia minimizando la demora: acelerando los procedimientos de la CIDH. Texas: The University of Texas School of Law, 2011.

9 Proceso de fortalecimiento en el Sistema Interamericano. Disponible [en línea] <http://www.oas.org/es/cidh/mandato/fortalecimiento.asp> [consulta: 4 de abril de 2014].

10 El 13 de diciembre de 2011 el Grupo de Trabajo Especial adoptó un informe que contiene 67 recomendaciones, entre ellas, 53 dirigidas a la CIDH. Véase: Informe del Grupo de trabajo especial de reflexión sobre el funcionamiento de la Comisión Interamericana de Derechos Humanos para el fortalecimiento del Sistema Interamericano de Derechos Humanos para la consideración del consejo permanente. OEA/Ser.G, GT/SIDH-13/11 rev.13, 13 de diciembre de 2011. El informe fue aprobado por el Consejo Permanente el 25 de enero de 2012 y acogido por la Asamblea General el 5 de junio de 2012. Disponible [en línea] <http://scm.oas.org/doc_public/SPANISH/HIST_11/ CP27754S04.doc> [consulta: 4 de abril de 2014]. Ver también: Resultado del proceso de reflexión sobre el funcionamiento de la Comisión Interamericana de Derechos humanos para el fortalecimiento del Sistema Interamericano de Derechos Humanos. AG/RES.1 (XLIV-E/13), 22 de marzo de 2013.

11 Se reforman los artículos 25, 28, 29, 30, 36, 37, 42, 44, 46, 59, 72, 76 y 79 de su reglamento, aprobado en su $137^{\circ}$ período ordinario de sesiones celebrado del 28 de octubre al 13 de noviembre de 2009 , y modificado el 2 de septiembre de 2011. Disponible [en línea] <http://www.oas.org/es/cidh/decisiones/pdf/Resolucion1-2013esp.pdf> [consulta: 4 de abril de 2014]. Artículos 76 y 46, respectivamente, del reglamento de la $\mathrm{CIDH}$.

13 Ver: OEA. Programa-Presupuesto de la organización. Aprobado por la Asamblea General durante el $45^{\circ}$ período extraordinario de sesiones. AG/RES.1 (XLV-E/13), octubre 2013. Disponible [en línea] <http://www.oas.org/budget/> [consulta: 4 de abril de 2014]. 
nas de sus facultades frente a la Corte IDH, a fin de enfocar sus esfuerzos en las cuestiones más primordiales de su mandato ${ }^{14}$.

El presente artículo tiene por objetivo analizar el rol de la CIDH en el proceso de supervisión de cumplimiento de sentencias y solicitud de reparaciones ante la Corte IDH, con el fin de esbozar algunas sugerencias que podrían permitir a la $\mathrm{CIDH}$ reformular su papel y fortalecer sus atribuciones, enfocando de manera más efectiva su trabajo e incrementando el impacto en sus pronunciamientos.

\section{Supervisión de cumplimiento de sentencias y el rol de la CIDH}

La Convención Americana sobre Derechos Humanos (CADH) no establece el procedimiento que debe guiar la supervisión de cumplimiento de sentencias, por lo que la Corte IDH ha afirmado su facultad de supervisión en su jurisprudencia mediante la interpretación de las normas de la $\mathrm{CADH}^{15}$.

Actualmente el artículo 69 del reglamento de la Corte IDH regula el procedimiento de supervisión de cumplimiento a través de la presentación de informes estatales y de las correspondientes observaciones a dichos informes por parte de las víctimas o sus representantes. Asimismo, señala que: "la Comisión deberá presentar observaciones al informe del Estado y a las observaciones de las víctimas o sus representantes".

Por su parte, el reglamento de la CIDH no regula la actuación de la misma en la supervisión de cumplimiento de sentencias ante la Corte IDH. No obstante, en su artículo 59 dispone que para la elaboración de su informe anual "utilizará información sobre el cumplimiento por parte del Estado de las recomendaciones de la Comisión y sentencias de la Corte". Asimismo, para efectos de la inclusión de un país en el Capítulo IV.B de su informe anual (países que incumplen con los derechos humanos), se tomarán en cuenta las "omisiones graves en la adopción de disposiciones necesarias para hacer efectivos los derechos fundamentales o para cumplir las decisiones de la Comisión y la Corte Interamericana"16.

A la fecha, la Corte IDH ha emitido 276 sentencias en casos contenciosos, de las cuales 160 han incluido sentencias de reparaciones, y respecto a 22 países de la región ${ }^{17}$. En el año 2013

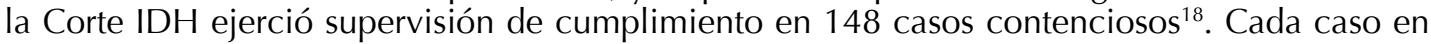

14 En particular, cabe señalar que la Corte IDH, en su organización interna, ha desarrollado a partir del 2014 la creación de una nueva Unidad de Supervisión de Cumplimiento de Sentencias, la cual pretende sistematizar la supervisión conjunta y estratégica de sus casos. Dicha práctica podrá permitir identificar factores comunes que presentan los casos, en relación con los diversos Estados y las principales temáticas en supervisión, a fin de ofrecer soluciones efectivas para su implementación. No obstante, el presente trabajo no se enfoca en el rol de la Corte IDH frente a la supervisión, sino en el de la $\mathrm{CIDH}$.

15 Corte IDH. Caso Baena Ricardo y otros Vs. Panamá. (Competencia). Sentencia de 28 de noviembre de 2003. Serie C No. 104; ver también: artículos 1.1, 2, 33, 62, 63.1, 65, 67, 68.1 de la CADH; artículos 25.1 y 30 de su estatuto y; 69 de su reglamento.

16 Artículos 59.5.b y 59.6.d.iii), respectivamente. Disponible [en línea] <http://www.oas.org/es/cidh/mandato/Basicos/ reglamentoCIDH.asp> [consulta: 4 de abril de 2014].

Casos contenciosos: disponible [en línea] <http://corteidh.or.cr/index.php/es/casos-contenciosos> [consulta: 21 de abril de 2014].

Informe anual de la Corte IDH año 2013, pendiente de publicación a la fecha de recepción de este artículo. En el año 2012, la Corte IDH ejercía supervisión de cumplimiento en más de 138 casos. Véase: Informe anual de la Corte IDH año 2012, p. 14. Disponible [en línea] <http://corteidh.or.cr/sitios/informes/docs/SPA/spa_2012.pdf> [consulta: 4 de abril de 2014]. 
supervisión tiene un promedio de entre 5 y 10 medidas activas que supervisar ${ }^{19}$. Muchas de ellas de gran complejidad, especialmente cuando se refieren a garantías de no repetición, tales como reformas legislativas ${ }^{20}$, estructurales ${ }^{21}$ o medidas de capacitación ${ }^{22}$, implementación de atención médica $^{23}$, o la efectividad en el deber de investigar ${ }^{24}$. Todas estas medidas pueden implicar cambios profundos y estructurales en el Estado, por lo que su debida implementación requiere de períodos considerables de tiempo.

Durante el año 2013, la Corte IDH emitió 26 resoluciones sobre supervisión de cumplimiento de sentencias y realizó 12 audiencias privadas de supervisión ${ }^{25}$.

Muchos de los casos respecto de los cuales la Corte IDH ejerce supervisión llevan más de 15 años en cumplimiento ${ }^{26}$. El promedio reciente de casos cerrados en su totalidad es de 3 por año, por lo que la supervisión de fallos es una labor que va incrementando constantemente ${ }^{27}$.

19 La Corte ha seguido un esquema de reparación integral, a través de la disposición de las siguientes medidas: i) deber de investigar, juzgar, y en su caso sancionar; ii) restitución; iii) rehabilitación; iv) satisfacción; v) garantías de no repetición; vi) indemnización compensatoria y; vii) costas y gastos. Lo anterior, tomando en consideración los principios y directrices básicos sobre el derecho de las víctimas de violaciones manifiestas de las normas internacionales de derechos humanos y de violaciones graves del derecho internacional humanitario a interponer recursos y obtener reparaciones. Ver: Asamblea General de Naciones Unidas. Principios y directrices básicos sobre el derecho de las víctimas de violaciones manifiestas de las normas internacionales de derechos humanos y de violaciones graves del derecho internacional humanitario a interponer recursos y obtener reparaciones. Resolución 60/147, 16 de diciembre de 2005. Disponible [en línea] <http://www2.ohchr.org/spanish/law/reparaciones.htm> [consulta: 4 de abril de 2014].

20 Véase por ejemplo, Corte IDH. Caso "La Última Tentación de Cristo" (Olmedo Bustos y otros) vs. Chile. Fondo, Reparaciones y Costas. Sentencia de 5 de febrero de 2001. Serie C No. 73, párr. 97, punto resolutivo cuarto; caso de la Masacre de las Dos Erres vs. Guatemala. Excepción Preliminar, Fondo, Reparaciones y Costas. Sentencia de 24 de noviembre de 2009. Serie C No. 211, párr. 242 y; caso Radilla Pacheco vs. México. Excepciones Preliminares, Fondo, Reparaciones y Costas. Sentencia de 23 de Noviembre de 2009. Serie C No. 209, párr. 339.

Corte IDH. Caso Pacheco Teruel vs. Honduras. Fondo, Reparaciones y Costas. Sentencia de 27 de abril de 2012. Serie C No. 241, párr. 96.

22 Corte IDH. Caso Goiburú y otros vs. Paraguay. Fondo, Reparaciones y Costas. Sentencia de 19 de noviembre de 2009, Serie C No. 153, párr. 49; caso De la Masacre de las Dos Erres Vs. Guatemala, op.cit, párr. 252 y; caso González y otras ("Campo Algodonero") vs. México. Excepción Preliminar, Fondo, Reparaciones y Costas. Sentencia de 16 de noviembre de 2009. Serie C No. 205, párr. 540.

Corte IDH. Caso Barrios Altos vs. Perú. Reparaciones y Costas. Sentencia de 30 de noviembre de 2001. Serie C No. 87, párr. 42 (de conformidad al acuerdo realizado con el Estado y que es homologado por la Corte IDH como consta en el párrafo 45) y; caso Chitay Nech y otros vs. Guatemala. Excepciones Preliminares, Fondo, Reparaciones y Costas. Sentencia de 25 de mayo de 2010. Serie C No. 212, párrs. 255 y 256.

Corte IDH. Caso de la Masacre de las Dos Erres vs. Guatemala, op.cit, párr. 231; caso Chitay Nech y otros vs. Guatemala, op.cit, párr. 232 y; caso Contreras y otros vs. El Salvador. Fondo, Reparaciones y Costas. Sentencia de 31 de agosto de 2011. Serie C No. 232, párr. 183.

Informe anual de la Corte IDH año 2013, op.cit. Lo anterior se debe a que la Corte inició en el año 2010 la práctica de realizar audiencias de supervisión relativas a un mismo Estado, pero referentes a más de un caso cuando se trata de medidas de reparación que guardan semejanza temática entre sí. Durante el 2012, la Corte emitió 32 resoluciones sobre supervisión de cumplimiento de sentencia y realizó 5 audiencias privadas y 1 audiencia pública, relativas a 14 casos. Véase, informe anual de la Corte IDH año 2012, op. cit, p.14. Ibídem, p.14 a 17.

Ídem. Cabe destacar que en el año 2012 se cerraron tres casos: Escher vs. Brasil, Lori Berenson Mejía vs. Perú y Mejía Idrovo vs. Ecuador. En el año 2013, se cerraron los casos: Castañeda Gutman vs. México, Abril Alosilla y otros vs. Perú y Kimel vs. Argentina. 
Tabla 1. Casos contenciosos en supervisión de cumplimiento de sentencia ${ }^{28}$

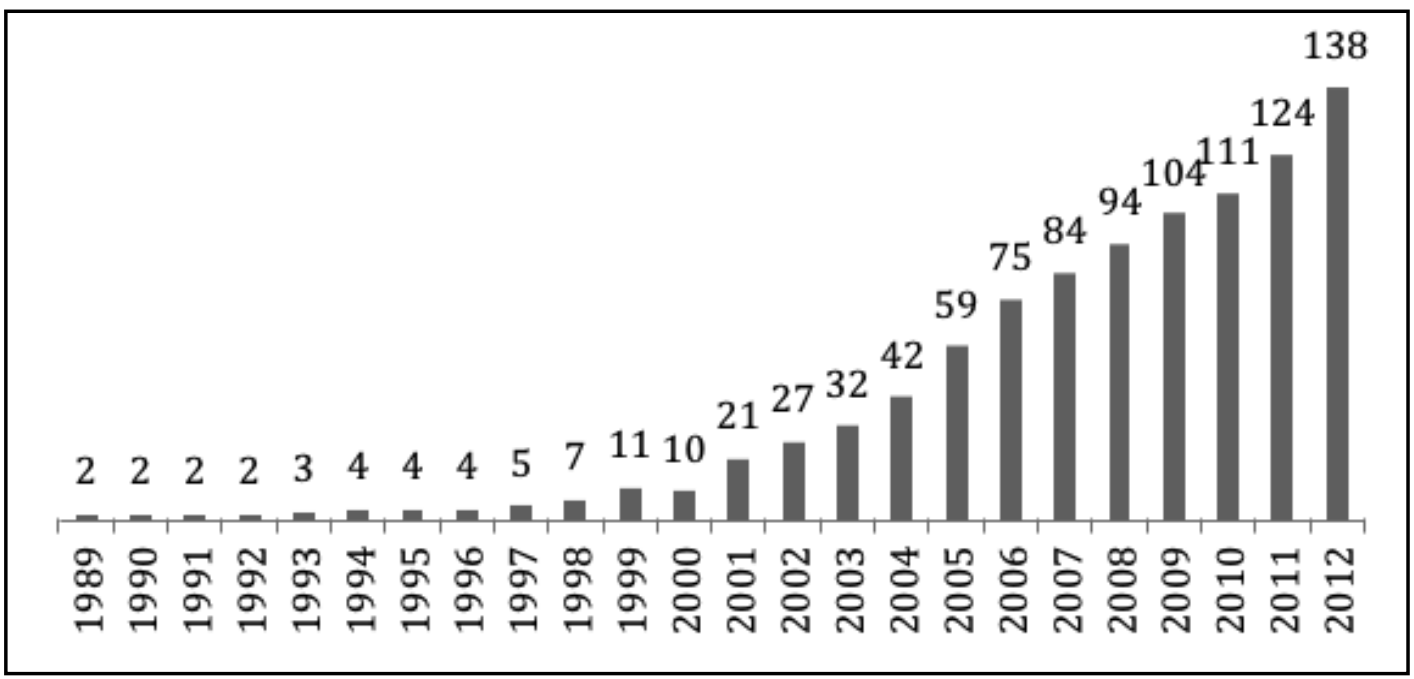

La práctica de la Corte IDH en la supervisión de cumplimiento, consiste en que al emitir sus sentencias que contengan medidas de reparación, otorga a los Estados el plazo de un año para remitir un informe sobre el cumplimiento o avance de cada medida según sea el plazo que le haya estipulado a las mismas ${ }^{29}$. Una vez vencido ese plazo, la Corte IDH continúa supervisando los puntos pendientes de cumplimiento, pudiendo emitir, como primer mecanismo, una resolución de supervisión de cumplimiento de conformidad con el artículo 69 de su reglamento. La práctica reiterada de la Corte IDH en esta materia -a través de sus resoluciones- ha consistido, por lo general, en solicitar informes periódicos trimestrales ${ }^{30}$ o remitir solicitudes semestralmente $^{31}$ a los Estados y otorgar el plazo de cuatro semanas para que los representantes de las víctimas remitan sus observaciones y posteriormente, otorgar dos semanas adicionales para que la $\mathrm{CIDH}$ remita las suyas ${ }^{32}$.

Lo anterior implica que en el período de un año se generan un promedio de entre 2 a 4 informes estatales por caso y la CIDH deberá remitir sus correspondientes observaciones a cada informe del Estado, incluyendo sus observaciones a la información remitida por los representantes. Si multiplicamos el número de informes estales de cada caso, por los 148 casos en supervisión al

28 Tabla elaborada por el autor.

29 La Corte IDH en sus sentencias otorga diferentes plazos para el cumplimiento de medidas. Por lo general de un año, otras con plazos específicos, y otras para ser cumplidas dentro de un "plazo razonable".

30 En general y en años recientes, la Corte IDH ha solicitado estos informes periódicos, a través de sus resoluciones de supervisión. Véase, por ejemplo: Corte IDH. Caso Chitay Nech y otros vs. Guatemala. Supervisión de Cumplimiento de Sentencia. Resolución de la Corte Interamericana de Derechos Humanos de 22 de agosto de 2013, punto resolutivo 5; caso González y otras ("Campo Algodonero") vs. México. Supervisión de Cumplimiento de Sentencia. Resolución de la Corte Interamericana de Derechos Humanos de 21 de mayo de 2013, punto resolutivo 4 y; caso Gelman vs. Uruguay. Supervisión de Cumplimiento de Sentencia. Resolución de la Corte Interamericana de Derechos Humanos 20 de marzo de 2013, punto resolutivo 6.

31 No obstante, la Corte IDH también ha realizado solicitudes de información, a través de cartas emitidas por la Secretaría del tribunal, siguiendo instrucciones del presidente de la Corte IDH. En algunos casos, otorgando plazos de tres meses, pero en algunos otros casos con una fecha específica, por lo que en esos supuestos se podría desprender un promedio de solicitud de informes semestralmente.

Véanse puntos resolutivos de las resoluciones de supervisión de cumplimiento. 
2013, la CIDH estaría emitiendo un aproximado de entre 296 a 592 escritos de observaciones al año respecto de informes del Estado y observaciones de los representantes. Para efectos de estadística podemos determinar un promedio de 444 informes sobre observaciones al año; es decir, un promedio de más de 1.2 escritos por día calendario.

De igual forma, si consideramos un promedio de 6 medidas activas por caso $^{33}$, muchas de ellas de alto grado de complejidad, la $\mathrm{CIDH}$ deberá referirse a la situación de un promedio de al menos 2.664 medidas a través de las 444 (aproximadamente) observaciones escritas que debe remitir a la Corte IDH. A lo anterior, se deben agregar las observaciones que la CIDH realiza en la supervisión de medidas provisionales ${ }^{34}$.

Con motivo del incremento constante de casos en supervisión, las observaciones que remite la $\mathrm{CIDH}$ se han limitado a resumir la posición de las partes y establecer algún tipo de valoración general sobre la información planteada, o han reiterado la posición de los representantes, pero en muchos casos se ha carecido de una valoración cualitativa más allá de la que se desprende del resumen de la información aportada ${ }^{35}$.

Cada vez, de manera más recurrente, la CIDH se ha visto en la necesidad de solicitar prórrogas para remitir sus escritos de observaciones, en algunos casos demorando su remisión o señalando no tener observaciones al respecto. Dichas dilaciones, así como las de otras partes, van retardando el proceso de informes periódicos y ha generado que la Secretaría de la Corte IDH emita reiteraciones de solicitud de información para poder proseguir con el acostumbrado trámite de observaciones y contra observaciones. Por ejemplo, en el caso Campo Algodonero, la Corte IDH luego de varias reiteraciones a la $\mathrm{CIDH}$, rechazó sus observaciones por extemporáneas ${ }^{36}$. Al respecto, la Corte IDH señaló que:

[...] la falta de presentación, por parte de los representantes, y la extemporaneidad del escrito de la Comisión Interamericana, respecto a las observaciones al tercer informe del Estado, dificulta el proceso de implementación de la Sentencia y una evaluación integral de las medidas adoptadas por el Estado. Ello es particularmente problemático en un caso como el presente, donde, como respuesta a las órdenes emitidas por el Tribunal, fueron adoptadas un alto número de gestiones en los niveles local y federal de toda la nación mexicana. Sin perjuicio de lo anterior, la Corte reseñará las observaciones pertinentes presentadas por la Comisión y los representantes al primer y segundo informe remitido por el Estado.

Otro elemento adicional a tomar en consideración, consiste en que los Estados -en general- no se están refiriendo a las observaciones de la $\mathrm{CIDH}$ en sus informes, ya que centran su atención en los planteamientos de los representantes, que son quienes insisten en el cumplimiento y/o están sufriendo las repercusiones o no de la implementación del fallo ${ }^{37}$. En este sentido, y con motivo de lo anterior, la Corte IDH en sus resoluciones de supervisión de cumplimiento ha reducido las consideraciones respecto de la información que aporta la $\mathrm{CIDH}$, centrando su eva-

33 Por ejemplo: Corte IDH. Caso Anzualdo Castro vs. Perú. Supervisión de Cumplimiento de Sentencia. Resolución de la Corte Interamericana de Derechos Humanos de 21 de agosto de 2013, puntos resolutivos 2 y 3 y caso González y otras ("Campo Algodonero") vs. México. Supervisión de Cumplimiento de Sentencia, op.cit, punto resolutivo 2.

34 Para el año 2013, la Corte IDH contaba con la supervisión de más de 26 medidas provisionales. Información disponible en informe anual de la Corte IDH año 2013, op.cit.

35 Cfr. Expedientes de supervisión de cumplimiento de sentencias. Corte IDH. Caso González y otras ("Campo Algodonero") vs. México. Supervisión de Cumplimiento de Sentencia, op.cit, visto 8 y considerandos 8 a 10 .

37 Ver, por ejemplo: Corte IDH. Caso Loayza Tamayo vs. Perú. Supervisión de Cumplimiento de Sentencia. Resolución de la Corte Interamericana de Derechos Humanos de 6 febrero de 2008, considerando 16. 
luación en la discusión que se genera entre las partes. Esto deriva en la falta de efectividad real de las observaciones escritas de la $\mathrm{CIDH}$ en el proceso de supervisión de cumplimiento ante la Corte $\mathrm{IDH}^{38}$.

No obstante lo anterior, se registra que la presencia de la CIDH en las audiencias de supervisión de cumplimiento ha sido fundamental para la valoración de los estados en que se encuentra la supervisión, y en muchos otros casos, para alcanzar conciliaciones entre las partes, lo que deriva en cumplimientos efectivos ${ }^{39}$.

Por otro lado, podemos observar que el modelo de informes del Estado y observaciones, proviene del reglamento anterior, cuando la $\mathrm{CIDH}$ era la parte actora y principal en el proceso de representación de las víctimas ante la Corte IDH, por lo que era necesario que tutelara la integralidad de la implementación de cada punto de la sentencia. No obstante, con la reforma reglamentaria de 2009, el rol de la CIDH cambió, ya no siendo una parte más en el proceso, sino el órgano que remite el caso a la Corte IDH luego del dictamen del informe de fondo y el garante del orden público interamericano. Frente a ello, la debida implementación de la sentencia le corresponde principalmente a las partes del caso ante la Corte IDH; es decir, al Estado y los representantes, de manera que la CIDH pueda centrar su atención en las cuestiones trascendentales de la implementación de las medidas más relevantes para el SIDH. Para lograr este objetivo, a continuación se sugieren medidas específicas que se pueden adoptar en el SIDH.

Primero, se sugiere que de común acuerdo entre la Corte IDH y la $\mathrm{CIDH}$, la Corte IDH modifique el artículo 69 de su reglamento en el sentido que "la Comisión podrá, si lo estima pertinente, presentar observaciones al informe del Estado y a las observaciones de las víctimas o sus representantes", descargando así a la CIDH de este "deber". Segundo, que la CIDH establezca una estrategia de los casos o medidas específicas en las que amerite pronunciarse respecto de la supervisión, de manera que pueda priorizar en cuestiones sustantivas y cualitativas. De ser pertinente, incluir la nueva práctica de supervisión en su reglamento. Lo anterior debe estar relacionado también con los nuevos roles que el SIDH ha generado con las reformas recientes, enfocando también esta tarea de supervisión hacia cuestiones del orden público interamericano. Ello podría permitir utilizar dicho concepto de una manera creativa en favor de agilizar procesos de implementación relevantes en la región. En este sentido, la CIDH podría enfocar la supervisión a través de medidas temáticas para la región o en cuestiones relevantes o emergentes para determinado país, etc. Así, se podría reforzar también el trabajo de las relatorías de la $\mathrm{CIDH}$, a través de la implementación estratégica de temáticas específicas, inclusive con el mecanismo de visitas in loco ${ }^{40}$; esto permitiría además, solicitar a la Corte IDH audiencias con tales características y así atender problemáticas particulares que puedan contribuir a la no repetición de otros casos o la eventual solución indirecta, a través de ello, de otros casos pendientes ante la misma (efectos erga omnes del fallo). Finalmente, también se sugiere que la CIDH debe seguir participando en todas las audiencias de supervisión

38 Ver, por ejemplo: Corte IDH. Caso Vélez Loor vs. Panamá. Supervisión de Cumplimiento de Sentencia. Resolución de la Corte Interamericana de Derechos Humanos 13 de febrero de 2013, visto 4; caso Radilla Pacheco vs. México. Supervisión de Cumplimiento de Sentencia. Resolución de la Corte Interamericana de Derechos Humanos de 19 de mayo de 2011, considerando 39; caso de las Masacres de Ituango vs. Colombia. Supervisión de Cumplimiento de Sentencia. Resolución del Presidente de la Corte Interamericana de Derechos Humanos de 22 de diciembre de 2010, considerandos 17 y 41; caso Barrios Altos vs. Perú. Supervisión de Cumplimiento de Sentencia. Resolución de la Corte Interamericana de Derechos Humanos de 4 de agosto de 2008, considerandos 12 y 46 y; caso "Instituto de Reeducación del Menor" vs. Paraguay. Supervisión de Cumplimiento de Sentencia. Resolución de la Corte Interamericana de Derechos Humanos de 19 de noviembre de 2009, visto 6 y considerando 36.

Ver, por ejemplo: Corte IDH. Caso de la Comunidad Mayagna (Sumo) Awas Tingni vs. Nicaragua. Supervisión de Cumplimiento de Sentencia. Resolución de la Corte Interamericana de Derechos Humanos de 7 mayo de 2008.

Al respecto, en los años 2007 y 2011, la Relatoría de Pueblos Indígenas de la CIDH realizó visitas con estas características en Paraguay. Disponible [en línea] <http://www.oas.org/es/cidh/indigenas/actividades/paises.asp> [consulta: 7 de abril de 2014]. 
de cumplimiento ante la Corte IDH con base en las buenas prácticas y experiencias logradas y su rol de garante del SIDH.

\section{Fortalecimiento de la CIDH en el planteamiento de medidas de reparación integral ante la Corte IDH}

El artículo 63.1 de la CADH faculta a la Corte IDH a ordenar reparaciones de manera integral ${ }^{41}$. En este entendido, la Corte IDH ha emitido más de 160 sentencias de reparaciones.

En el primer reglamento de la Corte IDH de 1980, la CIDH era quien presentaba la demanda del caso ante la Corte IDH y representaba a la víctima en todas las etapas, lo cual implicaba que en la audiencia pública, la $\mathrm{CIDH}$ en ocasiones acreditaba a las víctimas como asesores de la CIDH para el caso. Con la reforma de 1996, se dio acceso a las víctimas a intervenir en la audiencia al exponer sus pretensiones en materia de reparaciones, lo cual implicó escuchar las afectaciones específicas de las víctimas y sus necesidades para restablecer su situación. Con la reforma reglamentaria de 2000, se incluyó la posibilidad de que las víctimas participaran de modo autónomo e independiente en todas las etapas del proceso (excepciones preliminares, fondo y reparaciones), a través de su escrito de solicitudes, argumentos y pruebas (ESAP) y en las audiencias, alegatos finales, e interpretación del fallo. Finalmente, con la reforma de 2009, se dio participación plena y activa a las víctimas como parte procesal del litigio junto con el Estado demandado ${ }^{42}$.

En la fase en que la CIDH presentaba demandas ante la Corte IDH, luego de la reforma del año 2000, la CIDH -en algunos casos- se limitó a reiterar sus recomendaciones del informe de fondo, solicitando a la Corte IDH que determinara las reparaciones correspondientes, sin hacer un análisis exhaustivo o puntual de la necesidad de las mismas ${ }^{43}$. A partir de la reforma de 2009, la $\mathrm{CIDH}$ ha establecido la práctica consistente en que, al remitir el escrito de sometimiento del caso a la Corte IDH, señala que "además, la Comisión solicita a la Corte que ordene al Estado que [...]", y para ello repite las recomendaciones que estableció en su informe de fondo, las cuales en la mayoría de los casos, son genéricas ${ }^{44}$. En este sentido, la CIDH podría estar desperdiciando una oportunidad única para profundizar en la elaboración de sus propias medidas a la luz de problemáticas complejas y estructurales.

El artículo 50 de la CADH establece que la $\mathrm{CIDH}$ en su informe de fondo podrá formular las posiciones y recomendaciones que juzgue adecuadas. El artículo 44.2 del reglamento de la $\mathrm{CIDH}$ reitera su facultad de establecer recomendaciones al Estado e imponer plazos para su cumplimiento. Asimismo, el artículo 44.3.c de su reglamento establece que si el peticionario quiere que el caso sea sometido ante la Corte IDH, deberá presentar como uno de los elementos

41 El artículo 63.1 de la CADH dispone que "cuando decida que hubo violación de un derecho o libertad protegidos en esta Convención, la Corte dispondrá que se garantice al lesionado en el goce de su derecho o libertad conculcados. Dispondrá asimismo, si ello fuera procedente, que se reparen las consecuencias de la medida o situación que ha configurado la vulneración de esos derechos y el pago de una justa indemnización a la parte lesionada".

CALDERÓN, Jorge. "La reparación integral en la jurisprudencia de la Corte IDH: estándares aplicables al nuevo paradigma mexicano". En: FERRER MAC-GREGOR, Eduardo, CABALLERO, José Luis y STEINER, Christian (Coord.). Derechos Humanos en la Constitución Política de los Estados Unidos Mexicanos: comentarios y jurisprudencia constitucional e interamericana. México D.F: Fundación Konrad Adenauer Stiftung, Suprema Corte de Justicia de la Nación Mexicana e Instituto de Investigaciones Jurídicas UNAM, 2013, pp.157-160. Disponible [en línea] <http:// biblio.juridicas.unam.mx/libros/8/3567/11.pdf > [consulta: 7 de abril de 2014]. tenciosos> [consulta: 7 de abril de 2014].

Véase sometimientos de casos. Disponible [en línea] <http://www.oas.org/es/cidh/decisiones/demandas.asp $>$ [consulta: 7 de abril de 2014]. 
"las pretensiones en materia de reparaciones y costas". El artículo 74 del mismo señala que la CIDH podrá remitir cualquier otra información que considere útil para el conocimiento del caso ante la Corte IDH.

Por su parte, el artículo 35 del reglamento de la Corte IDH establece que en la remisión del sometimiento del caso, la Comisión deberá enviar "d) las pretensiones, incluidas las referidas a reparaciones".

En este sentido, considero que la $\mathrm{CIDH}$ puede formular pretensiones de reparaciones más allá de lo establecido en su informe de fondo. Las medidas dispuestas mediante sus recomendaciones deben estar sujetas a plazos prudenciales para que el Estado pueda darles cumplimiento (artículo 44 de su reglamento), lo que significa medidas realizables en plazos breves, por lo que puede excluir per se la disposición de garantías de no repetición de gran complejidad, como podrían ser ciertas reformas legislativas, capacitaciones o restructuraciones institucionales. Mientras que las medidas de reparación integral (artículo 63.1 de la CADH) que se pueden someter en un caso contencioso ante la Corte IDH, como instancia última, y mediante el proceso de peritajes y contradictorio, representarán medidas más amplias y con plazos proporcionales a cada medida.

En razón de lo anterior, se sugiere lo siguiente para fortalecer el rol de la CIDH en el planteamiento de reparaciones ante la Corte IDH. Por una parte, que en el sometimiento del caso ante la Corte IDH, la CIDH reformule y profundice las medidas señaladas en su informe de fondo y plantee estratégicamente las reparaciones solicitadas, de acuerdo con la clasificación habitual que hace la Corte IDH respecto de medidas de "reparación integral": restitución, rehabilitación, satisfacción, garantías de no repetición, deber de investigar, y compensación y, de ser pertinente, remitir la solicitud que hace el peticionario, de acuerdo con el artículo 44.3.c del reglamento de la $\mathrm{CIDH}$. Asimismo, la CIDH debe enfocarse principalmente en las garantías de no repetición del caso (como garante del orden público interamericano) y debe detectar cuestiones que puedan trascender dicho orden público interamericano para efectos de las medidas de reparación, las cuales acrediten el nexo de causalidad con el $\mathrm{caso}^{45}$, y de ser necesario, proponer los peritajes correspondientes, de conformidad con el artículo 35.1.f. del reglamento de la Corte IDH (como en la práctica lo ha venido realizado en varios $\operatorname{casos}^{46}$ ).

\section{Conclusiones}

En vista del escenario anteriormente descrito, resulta pertinente que la CIDH pueda reforzar sus facultades respecto de las temáticas abordadas, considerando la relevancia que tiene para el SIDH la reparación integral y la debida implementación de dichas medidas. Son muchos los resultados trascendentales que se han generado en la región a partir de estos dos componentes ${ }^{47}$,

45 "Este Tribunal ha establecido que las reparaciones deben tener un nexo causal con los hechos del caso, las violaciones declaradas, los daños acreditados, así como con las medidas solicitadas para reparar los daños respectivos. Por lo tanto, la Corte deberá observar dicha concurrencia para pronunciarse debidamente y conforme a derecho". Corte IDH. Caso Ticona Estrada y otros vs. Bolivia. Fondo, Reparaciones y Costas. Sentencia de 27 de noviembre de 2008. Serie C No. 191, párr. 110; caso de la Masacre de las Dos Erres vs. Guatemala, op.cit, párr. 227, y caso Fontevecchia y D'Amico vs. Argentina. Fondo, Reparaciones y Costas. Sentencia de 29 de noviembre de 2011. Serie C No. 238, párr. 99.

Véase sometimientos de casos 2013 y 2014. Disponible [en línea] <http://www.oas.org/es/cidh/decisiones/demandas.asp> [consulta: 7 de abril de 2014].

A modo de ejemplo, ver el nuevo paradigma mexicano en materia de protección de los derechos humanos a partir de las sentencias de la Corte IDH, y tan solo el tema del "control de convencionalidad". Corte IDH. Caso Radilla Pacheco vs. México. Supervisión de Cumplimiento de Sentencia, op.cit, considerando 5: "La Corte observa que el 14 de julio de 2011 la Suprema Corte de Justicia de la Nación de México (en adelante 'la Suprema Corte' o 'la SCJN') emitió un 'Acuerdo del Tribunal Pleno' dentro del expediente 'Varios 912/2010', mediante el cual expuso las obligaciones concretas del Estado mexicano, y en particular, del poder judicial de la Federación, a raíz de la 
por lo que la $\mathrm{CIDH}$ como -garante del orden público interamericano- tiene la oportunidad y misión de reforzar su incidencia al respecto.

En relación con las sugerencias sobre la supervisión de cumplimiento, el resultado práctico de estas medidas sería descargar a la CIDH, y en específico al grupo que se encarga en la de todos los asuntos frente a la Corte IDH ("Grupo Corte"), del deber de remitir observaciones en tiempo (más de 400 por año), respecto de cada uno de los más de 148 casos en supervisión y cada una de las más de 2.600 medidas (aproximadamente) en supervisión, con todo lo que esto significa en tiempo hombre/mujer, tramitación de su Secretaría, tiempos de flujos de información, con el posible bajo impacto que puedan tener estas observaciones en las resoluciones de la Corte IDH. Esto permitiría enfocar y priorizar una supervisión estratégica que permita a la CIDH tutelar el orden público interamericano en la región, a través de una debida implementación de los puntos más relevantes de las sentencias. Cabe mencionar que lo mismo podría aplicarse en los casos de supervisión de medidas provisionales solicitadas por los representantes ante la Corte $\mathrm{IDH}$, una vez que sea emitida la sentencia ${ }^{48}$.

Adicionalmente, es preciso señalar que la Asamblea General de la OEA debería tener mayor influencia en el seguimiento de los incumplimientos de sentencias informados por la Corte IDH (con fundamento en el artículo 65 de la CADH), para lo cual sería pertinente la creación de un "Grupo de Trabajo" o "Comisión" especializados para dar seguimiento político a esta cuestión, de la cual depende la legitimidad del SIDH, así como de toda la OEA.

Resultará relevante la interlocución que pueda establecer la CIDH con los órganos de la OEA, respecto de las prácticas que pueda ir impulsando la unidad de supervisión de cumplimiento de la Secretaría de la Corte IDH.

Respecto de las sugerencias en el planteamiento de reparaciones, es preciso reiterar la relevancia de las reparaciones en el SIDH y por ende, la participación de la CIDH en su debida formulación, análisis, e implementación. Esta práctica incluiría reforzar el rol de la CIDH en cuanto a la solicitud de medidas tales como las garantías de no repetición y otras de especial trascendencia, y así salvaguardar posibles problemáticas estructurales o impulsar la solución de otros casos similares. Lo anterior permitiría una congruencia y definición en cuanto a los puntos a enfocar en la supervisión de cumplimiento, de conformidad a lo establecido en el apartado de supervisión.

En conclusión, el primer planteamiento podría ser resuelto por un acuerdo y una reforma reglamentaria por parte de la Corte IDH y no debería ser un aspecto que afectara los procesos que

Sentencia emitida en el caso Radilla Pacheco [...] Mediante dicho fallo, la SCJN manifestó que el poder judicial está obligado a ejercer un control de convencionalidad ex officio entre las normas internas y la Convención Americana, y que para ello, debe tener en cuenta el marco del artículo 1 de la Constitución mexicana, el cual, a partir de la reforma de 10 de junio de 2011, establece que '[l]as normas relativas a los derechos humanos se interpretarán de conformidad con [la] Constitución y con los tratados internacionales de la materia favoreciendo en todo tiempo a las personas la protección más amplia'. Además, en el mencionado Acuerdo se indicó que las decisiones de la Corte Interamericana con respecto a México, y en particular la Sentencia emitida en el caso Radilla Pacheco [....], 'son obligatorias para todos los órganos [del Estado...] en sus respectivas competencias [...]. Por tanto, para el Poder Judicial son vinculantes no solamente los puntos de resolución concretos de la sentencia, sino la totalidad de los criterios contenidos en la sentencia mediante la cual se resuelve ese litigio. Por otro lado, el resto de la jurisprudencia de la Corte Interamericana que deriva de las sentencias en donde el Estado mexicano no figura como parte, tendrá el carácter de criterio orientador de todas las decisiones de los jueces mexicanos, pero siempre en aquello que sea más favorecedor a la persona [...]'. Asimismo, mediante dicho Acuerdo, la SCJN también estableció que 'el fuero militar no podrá operar bajo ninguna circunstancia frente a situaciones que vulneren derechos humanos de civiles', ya que éstos tienen el derecho a 'someterse a la jurisdicción de un juez o tribunal ordinario'".

Supuesto de los artículos 27.3 y 27.7 del reglamento de la Corte IDH. Si bien el estudio de estas facultades no fueron objeto de este artículo, es posible extender las consideraciones realizadas a la labor de supervisión en el cumplimiento de las medidas provisionales. 
actualmente atraviesa el SIDH, sino que por el contrario, sería coherente con los nuevos roles establecidos y un direccionamiento más efectivo en los recursos y medidas con que cuenta el sistema. El segundo planteamiento, se puede hacer efectivo ejerciendo de manera consciente y más efectiva, la facultad que le otorga el artículo 35 del reglamento de la Corte IDH a la CIDH en cuanto a las pretensiones en materia de reparaciones. Dos cuestiones sencillas, pero que a fin de cuentas son trascendentales para el fortalecimiento del SIDH y que trae consecuencias positivas para los beneficiarios del mismo y los estándares aplicables para toda la región.

Recibido: 4 de noviembre 2013

Aceptado: 28 de febrero 2014 